\title{
HIV/AIDS: A Persistent Health Issue for Women and Children in Mid and Far Western Nepal
}

\author{
Awasthi KR, ${ }^{1}$ Adefemi K, ${ }^{1}$ Tamrakar $\mathrm{M}^{2}$
}

\author{
${ }^{1}$ School of Public Health \\ Faculty of Health Sciences \\ Curtin University, Bentley 6102, WA \\ ${ }^{2}$ Department of Dentistry \\ Kathmandu University School of Medical Sciences \\ Dhulikhel, Kavre
}

\section{Corresponding Author}

Kiran Raj Awasthi

School of Public Health

Faculty of Health Sciences

Curtin University, Bentley 6102, WA

E-mail: kiranraj.awasthi@postgrad.curtin.edu.au

Citation

Awasthi KR, Adefemi K, Tamrakar M. HIV/AIDS: A Persistent Health Issue for Women and Children in Mid and Far Western Nepal. Kathmandu Univ Med J 2015;49(1):88-93.

\begin{abstract}
This article reviews the effect of male migration on the spread of HIV infections in mid and far-western Nepal. It explains the link between male mobility and HIV in women and children. Materials were collected by a systematic search of the databases and the websites of national and international agencies. HIV infection amongst male migrants was found to be high. Their risk behaviors such as unprotected sex with multiple partners and sex workers increase the risk of HIV infection. Substance abuse, loneliness, separation from families, peer pressure, long working hours and poor living conditions are factors that promote unsafe sex. Literacy and awareness about HIV is a key measure to decrease the prevalence of the disease and reduce social stigma among people affected. HIV is a major public health issue especially in Nepal with migration playing a major role in its spread. Negligence to sexual health and lack of comprehensive knowledge on the disease among male migrants are the major obstacles that have exacerbated the disease. There is a need for further research on the existing HIV cases affecting women and children of these two regions to get a clear picture of the gravity of the disease.
\end{abstract}

\section{KEYWORDS}

Conflict, HIV/AIDS, migration, sex workers, social stigma, South East Asia

\section{INTRODUCTION}

Acquired Immune Deficiency Syndrome (AIDS) caused by the Human Immunodeficiency Virus (HIV) is a concerning public health problem in mid and far-western Nepal. Nepal has seen a continuous increase in the number of HIV/AIDS cases since it was first detected in $1988 .{ }^{1-3}$ Women and children especially in rural areas of the country have been exposed to this devastating disease mainly through their spouses and parents respectively. The constant migration of the Nepalese male population to India in search of work is found to be one of the leading causes of HIV in Nepal. ${ }^{4,5}$ Continued efforts have been made over the last decade to address this escalating health issue but illiteracy combined with a lack of knowledge about the disease has slowed down the process. For a poor developing country like Nepal, the effect of HIV /AIDS is economically significant.

This article reviews the situation of HIV/AIDS in mid and far-western Nepal. It evaluates various studies and the epidemiological surveys conducted by various organizations to obtain the real picture of the disease burden. The main objective of the review is to elucidate how a migrating male population contribute significantly to the spread of HIV among women and children. It will also look to answer why the population in far-western Nepal are more vulnerable to this problem.

\section{Disease burden}

\section{Global HIV burden}

An estimated 33 million people around the world are living with HIV. ${ }^{6}$ Even after three decades since the first case of HIV was reported; it still persists as a major disease burden globally. Although studies showed a significant increase in the number of HIV cases by $27 \%$ between 1999 and 
2009, the number of deaths caused by it has decreased considerably in recent times. ${ }^{7}$ Most of this has been possible due to increased supply and use of antiretroviral drugs to infected persons. It has been reported that 6.65 million people with HIV have received antiretroviral treatment which is a $47 \%$ increase since $2003 .{ }^{6}$ Over the years, women have constituted nearly half of the total disease burden. ${ }^{8}$ A total of 3.4 million children under 15 years were living with HIV in 2010 which included 390,000 new cases. ${ }^{6}$

\section{HIV/AIDS in Nepal}

Nepal is low economic developing county in South East Asia with a total land area of 147,181 square kilometres with a population of $26,494,504 .^{9,10}$ It is bordered by India in the South, East and West while China shares the Northern boundary. Nepal is divided into five administrative developmental regions: eastern, central, western, midwestern and far-western. A majority of population (83\%) in Nepal currently live in the rural areas. ${ }^{10}$ Around $23 \%$ of the total population are concentrated in the mid and far-western region of the country. ${ }^{10}$ Even then, limited road access and a comparatively lower development rate have been seen in these two regions making them the least developed part of the country. A national focus on attaining universal access to primary level education for all has achieved a minor increase in the literacy rate in the last couple of years. The current literacy rate of the country stands at $65.9 \%$ with the female literacy rate relatively lower at $57.5 \% .{ }^{10}$ The discrepancy in education among the two genders is even higher in the rural areas of the country.

Nepal has been classified by WHO in the group of countries showing a decreasing trend of new HIV/AIDS cases by more than $25 \%$. It was not long ago when Nepal was categorized alongside Vietnam, Cambodia as a country in transition with an increase in HIV related cases. ${ }^{11}$ The number of newly infected cases has dropped from 4,760 in 2009 to 1,437 in 2011. ${ }^{12,13}$ The government health sector annual report estimates that over 50,000 people are living with HIV/AIDS in Nepal in 2011. Out of this, $28.2 \%$ of the population is constituted by females between the age group of 15-49 years. ${ }^{13}$ This is a decrease by just $0.4 \%$ from the previous year which gives an indication of the vulnerability of the female population to HIV infection. The other population that is of concern are children who have been infected with HIV via their mothers. The average number of new cases amongst children aged 0-14 years in 2011 was reported to be $378 .{ }^{13}$ The same report shows figures of 157 children aged between 0-4 years with the virus in addition to the estimated 13,000 orphans it has left behind in the country.

The major risk groups for the transmission of HIV in Nepal are male migrant workers, injecting drug users, sex workers and their clients. ${ }^{1}$ Nepal experienced a decade long internal Maoist revolution between 1996 and 2006 resulting in more than 10,000 deaths. ${ }^{14,15}$ Insecurity and constant torture from the rebels and the state army made it difficult for the male population to stay in their villages. ${ }^{14}$ This had a direct impact on the increase in migration rate. ${ }^{14,15}$ Studies have shown that migration has an influence on the increase of HIV cases; this could be one of the major hidden reasons for its increase between 1998 and 2005. ${ }^{14,15}$

As many as 300,000 people are believed to have been displaced due to the conflict. ${ }^{14}$ During the conflict a majority of government structures including health centres and hospitals were demolished making access to these services impossible. ${ }^{14}$ Political instability in the post revolution era coupled with the country's poor economy has made the reconstruction and rebuilding a very slow process. ${ }^{14,15}$ These factors have combined to increase the flow of migration towards greener pastures and most significantly India. ${ }^{16}$ Such a migration is common in the mid and far-western region of Nepal, especially amongst males who have to fend for their families. ${ }^{16}$ Majority of the HIV transmission have been attributed to male migrant workers who contribute $27 \%$ of the total infection spread. ${ }^{9}$ It has been a trend that the male population in the mid and far-west travel to India in search of seasonal or even long term work. ${ }^{16}$ More than $55 \%$ of male migration in the far-west is directed towards India. ${ }^{9}$ Migration is so common in the far-west that at least one member of 50 to $80 \%$ of households in this region would have migrated to India in search of work. ${ }^{16}$ Estimates show that there are currently more than 3 million Nepalese workers in big cities such as Mumbai, Delhi, Chennai, and Punjab of India. ${ }^{16}$ Out of this population it is believed that $10 \%$ are infected with HIV. ${ }^{14}$

India has the largest prevalence of HIV cases in the world constituting one-eighth of the global burden. In 2005 alone, it was reported that 5.2 million were living with HIV. ${ }^{17}$

Majority of the HIV infection spread in India is through existing sex brothels while the regular movement of truck drivers have added more impetus to the situation. ${ }^{18}$ Visits to these brothels and practice of unsafe sex are common amongst the migrant workers, which increase their risk of contacting the HIV infection. ${ }^{16,19}$ The direct impact of their infection is evident upon their return to Nepal during vacation when they spread the disease to their innocent wives, who in turn infect their children through delivery and breast feeding.

\section{METHODS}

There have been only few studies done on HIV/AIDS and its prevalence with respect to the Western region of Nepal. An extensive search was, therefore, conducted for research and review articles and eventually materials for this paper were compiled in different ways. First, a computer search was performed using the Google Scholar engine and Web of Knowledge to retrieve articles. The Google Scholar supported in retrieving articles published in local journals which could not be accessed via Web of Knowledge database. The search was limited to articles 
dating between 2001 and 2013 using the key words: HIV/ AIDS, Nepal, India, South East Asia, migration, sex workers, conflict and social stigma. The articles deemed relevant for the study were then searched individually, out of which 26 journal articles were selected, retrieved and reviewed. The articles selected were from peer reviewed journal from various disciplines such as social sciences, reproductive health, tropical disease, public health, adolescent health. Due to lack of studies on HIV/AIDS in Nepal, national journals of Nepal were also searched to retrieve relevant information. In addition to this, websites from various national and international agencies were also browsed. The national HIV fact sheets for the last three years were downloaded from the National Centre for AIDS and STD Control website. Similarly the WHO report and the UNAID report were obtained from their respective websites. The demographical and health related indicators for Nepal were obtained from the National Census data of 2011 and National Demographic Health Survey 2012 which were retrieved from the government websites.

\section{RESULTS AND DISCUSSION}

Spread of HIV in Nepal is commonly through the injection drug users, sex workers, client of sex workers and male migrants. ${ }^{19}$ Eastern Nepal has a considerable population of injection drug users while the Central, Western and Southern regions are now burdened by increase in female sex trade. ${ }^{24}$ Male migrant workers constitute the major epidemic risks in the mid and far-western region of the country (Fig 1).

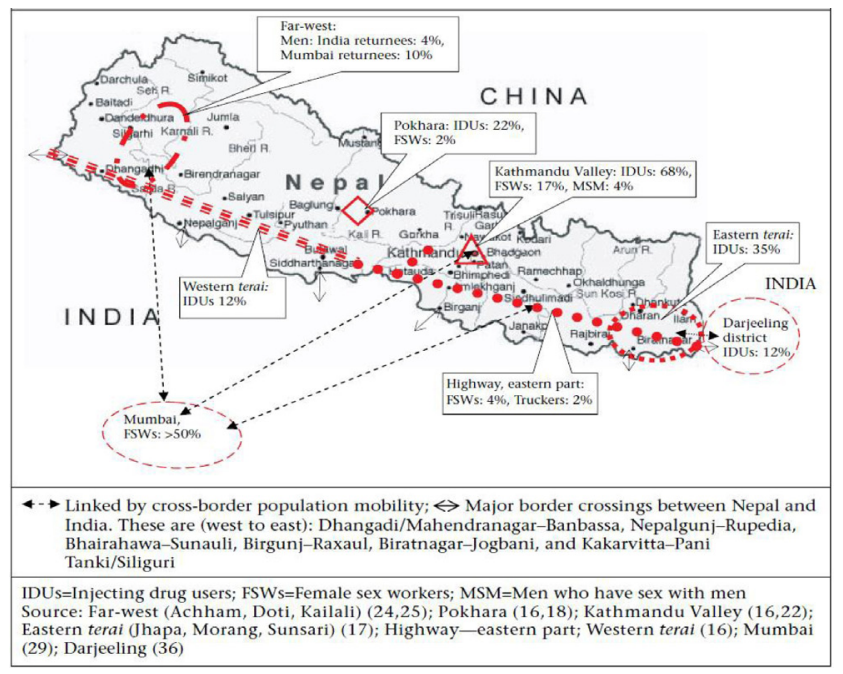

Figure 1. Map showing the approximate geographic locations of major HIV epidemics in Nepal and the major high prevalence groups in India with which they are linked through population mobility.

Source: Nepal B. Population Mobility and Spread of HIV across the Indo-Nepal Border. Journal of Health, Population and Nutrition. 2007;25(3):267-77
Migration has been one of the major contributors of the disease in Nepal. Both internal and external migration is common in Nepal. ${ }^{19}$ Displacement during the internal conflict, search for better opportunities and tertiary education have all contributed to internal mobility, whereas the cause of external migration is predominantly for seasonal or full time work. ${ }^{14,15,19}$ An estimated $66 \%$ of the male workers from the southern belt of Nepal and $55 \%$ from the far-western region migrate to India. Over $75 \%$ of these migrants are below the age of 30 years. ${ }^{9}$

\section{Internal migration and HIV}

Over 1.2 million migrate internally within the country with a majority being the male population. ${ }^{8}$ Two studies showed the impact of the conflict on the internal migration. ${ }^{14,15}$ Rural districts in the mid and far-western were the epicentre of the Maoist revolution and people in an around these areas were the most affected. ${ }^{14}$ Low socio economic status, threats and constant sexual abuse inflicted by both fighting parties resulted in an increase in male migration and female sex trade. ${ }^{14} \mathrm{~A}$ study among female sex workers indicated that $19 \%$ of them had entered the industry citing conflict as the main reason. ${ }^{14}$

Recent times have seen a considerable increase in number of female sex workers in urban cities and along the major East West highway in the South. This highway connects 29 out of a total 75 districts in Nepal. Nepal being a landlocked country depends on India for most of its supplies. Majority of the truck drivers travel this multiple day journey to supply goods to the cities in the middle hills. ${ }^{18}$ Even internal migrants working as drivers in the highways are exposed to this business. Unprotected sex is practiced by more than $70 \%$ of the truck drivers with studies showing that more than two thirds of the drivers have had experiences of having sex with a sex worker, at least once, during the course of their travels. ${ }^{14}$ Truck drivers have been found to be one of the major risk groups for HIV even in India. ${ }^{18,20}$ With these risk drivers travelling in and out of the country, there is also a potential threat for cross border spread. Nepal and India share an open border which increases the possibility of a networking of sex trades. Constant migration of the female sex workers back and forth between the countries could bring about an even worse consequence. ${ }^{4}$

\section{External migration and its consequences}

International migration follows a different trend based on the socioeconomic status of the population. The middle income and high income population in the Central Eastern region migrate to richer Gulf countries. ${ }^{21} \mathrm{~A}$ majority of the low socioeconomic strata in the mid-west and far-west choose the option of searching for work in India. An open border and no visa restrictions have made the process even more convenient. ${ }^{21}$ Metro cities in India like Mumbai, Chennai, Punjab and Delhi are constantly developing and filled with work opportunities. This makes it a better prospect for Nepalese migrants. ${ }^{4}$ India has the largest population affected with HIV in the world. It is estimated 
that 5.2 million people in the country are living with this disease. ${ }^{17}$ Out of this population, a considerable number is accounted for by the sex industry. ${ }^{22}$ A total of $71 \%$ of Mumbai sex workers were found to be HIV positive in 1997. ${ }^{19}$ With a majority of the male working population from the Far West pooled in Mumbai, it is no surprise that $10 \%$ of Mumbai returnees were found to be infected with HIV. This is $6 \%$ more than the average infection of male migrants in the Far West who have been infected with the disease. 4 Another study revealed a similar picture where $3.7 \%$ of external migrants, $3 \%$ of internal migrants and $0.7 \%$ of non-migrant population were infected by HIV. ${ }^{8}$

\section{Factors promoting risk behaviour}

Several factors promote risky sexual behaviours amongst migrant workers. Nepalese migrants in India normally are seen to take the low pay jobs despised by the locals, which involves long working hours and carrying heavy loads. A study conducted among the wives of migrant workers in Kailali district indicated $74 \%$ of the family receives as less as US \$ 65 a year from their spouses working abroad while $48 \%$ receive nothing. ${ }^{8}$ Majority of them were living on an amount that was insufficient for basic daily expenses. This indicates that the workers have considerable amount of money at their disposal which might increase the likelihood of indulging in risk behaviours such as high alcohol consumption and visit to brothels. Migrants often under the influence of alcohol are more likely to practice unprotected sex. ${ }^{23}$

A similar pattern is observed with Nepalese migrants in Mumbai where returnees have recalled peer pressure and being drunk as the reason for their visit to brothels. ${ }^{5}$ Young girls trafficked into the sex business are also forced to have sex with clients by intoxicating them. A large number of these girls due to the increased number of sexual contacts without use of condoms especially during the first month are a major source of HIV infection spread in Mumbai. ${ }^{24}$, 25 Poor living conditions owing to low income, a feeling of loneliness and separation from their families have been some of the major predisposing factors for migrants to get involved in sexual relationship with multiple partners including sex workers. ${ }^{23}$ Migrants spending more time away from home are found to indulged in third party sex within the first year and this phenomenon increases until the fourth year after which it ceases. ${ }^{23} \mathrm{~A}$ similar pattern was seen for migrants working in Mumbai. ${ }^{14}$

Moreover, lack of proper health facility, cost of treatment, the fear of social stigma and insecurity of job in case of positive results are some of the factors preventing migrants from undergoing screening tests. ${ }^{8,23}$ It is often observed that economic stability and prosperity brings about change in behaviour and increases negligence amongst migrants. They have a higher tendency to be involved in extramarital sex with multiple partners. ${ }^{23}$ Migrant returnees in the farwest showed a similar pattern by using their new found status in intimidating other women to have sex. Only less than $23 \%$ of men were found to be using condom during sex and were found to be involved with more than 2 sex partners which increases their exposure to HIV. ${ }^{5}$

\section{Literacy and its impact}

Multisectoral efforts to decrease HIV in recent years have started showing positive results. The number of HIV cases has dropped considerably since 2005. Figure 2 shows a decrease in the estimated HIV infections and prevalence between 2009 and 2011.

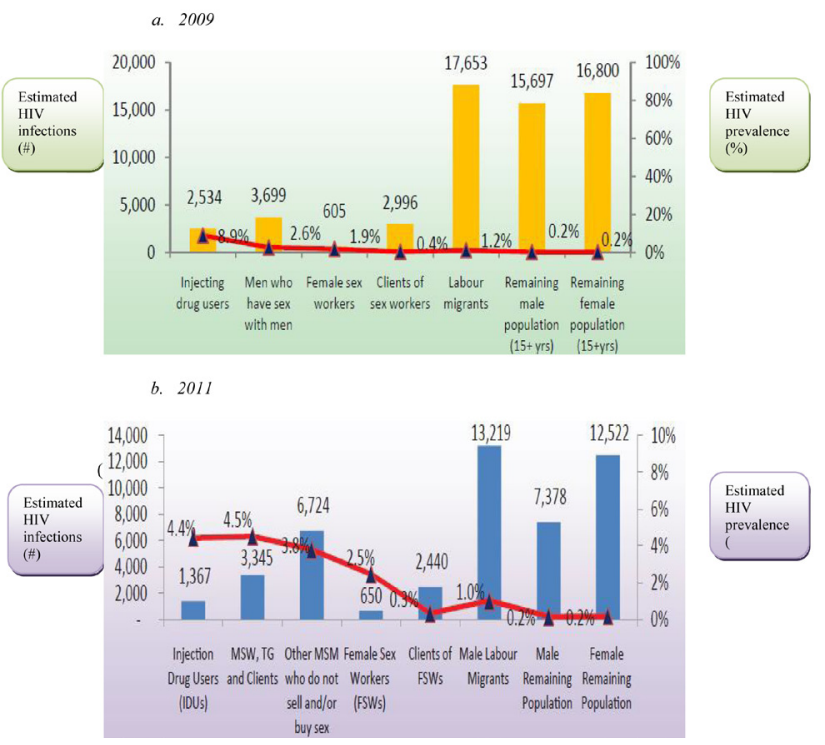

Figure 2. Estimated HIV Infections vs. Estimated HIV Prevalence (a.2009, b.2011)

Source: Source: National Centre for AIDS and STD Control. Factsheet $N^{\circ} 1$

Education and increased awareness have played a significant role in bringing about this change. Around $93 \%$ of the women in the Far West have now heard about HIV. ${ }^{9}$ The factor that however needs to be considered is the population of illiterate women residing in rural areas of the mid and far-western region. A study in Kailali district reported that $75 \%$ of the women population with formal education had knowledge about HIV and sexually transmitted diseases in contrary to $34 \%$ of those who did not. ${ }^{8}$ This gives a clear indication on how much literacy level impacts on the prevention and control of HIV.

There is, however, a lack of comprehensive knowledge about HIV amongst adolescents and in the general population. A considerable number of workers in garment and carpet factories in Nepal are teenagers. A study in carpet and garment industries in Kathmandu showed alarming results. Some of the respondents reported that they had their first sexual experience at the age of $13 .{ }^{26}$ It was found that $23 \%$ of males and $10 \%$ of females aged below 19 years had sex in the previous year with a majority of them without protection. ${ }^{26}$

Lack of adequate knowledge of the disease brings about the issue of social stigma amongst the infected population. It is seen that negative perception is created about people 
who are infected about HIV. ${ }^{27}$ From being denied health care facilities, jobs to being ostracised from the family and their society, the affected population at times are seen to even avoid medications and screenings. ${ }^{27}$ It is so unjust in some situations. However, on a positive note, a school in Thailand showed how a change in attitude can be brought about among small children by just providing them basic knowledge about HIV. Children with HIV who used to be despised and segregated by their friends saw a positive change in attitude immediately after understanding their innocence in acquiring their disease. ${ }^{28}$

\section{CONCLUSION AND RECOMMENDATIONS}

Lack of opportunities, comparatively slow development and poor socio economic conditions have all contributed to the increased rate of migration in Nepal. While the post conflict era has comparatively decreased population mobility rates, there is still the persistent risk of HIV spread through the fostering sex trade in the urban and southern areas of Nepal. Recent studies, have underlined HIV as a major public health issue in the western areas of Nepal that requires a definite need of attention. This review strongly indicates that male migration, either internal or external play a pivotal role in spread of HIV infection in the mid and far- western Nepal. This increased prevalence of HIV among migrant returnees increases the vulnerability and exposure of their wives to HIV. Negligence in sexual behaviour and lack of comprehensive knowledge on the disease among male migrants are the major obstacles that have exacerbated the disease.

As the risk of cross border spread of HIV between Nepal and India is high, there is a need for collaborative screening programs for migrants to be conducted at border areas on both sides. This will identify cases and give a clear picture of the prevalence of HIV among the migrants. There is also need for further research on HIV cases affecting women and children of the mid and far-western region to get a clear picture of the gravity of the disease.

\section{Competing interests}

This article is a review article and has no competing interest. It is simply aimed at providing information in general for people interested in preventing disease and promoting health.

\section{ACKNOWLEDGEMENT}

The author would like to gratefully acknowledge the time and effort given by the mothers and many health workers to our studies. The views expressed in this article are those of the authors, and do not necessarily reflect the policies of any organization.

\section{REFERENCES}

1. Furber A, Newell J, Lubben M. A systematic review of current knowledge of HIV epidemiology and of sexual behaviour in Nepal. TM \& IH Tropical medicine and international health. 2002;7(2):140-8.

2. Prasad S. Issues and challenges of HIV/AIDS prevention and treatment programme in Nepal. Global Journal of Health Science. 2009;1(2):62.

3. Gurung G, Suvedi BK. HIV/AIDS in Nepal. In: Lu Y, Essex M, Stiefvater E, editors. AIDS in Asia: Springer US; 2004. p. 115-21.

4. Nepal B. Population Mobility and Spread of HIV Across the Indo-Nepal Border. Journal of Health, Population and Nutrition. 2007;25(3):26777. PubMed PMID: 202992388;18330059. English.

5. Poudel KC, Jimba M, Okumura J, Joshi AB, Wakai S. Migrants' risky sexual behaviours in India and at home in far western Nepal. Tropical Medicine \& International Health. 2004;9(8):897-903.

6. World Health Organization. Global HIV/AIDS Response: Epidemic Update and Health Sector Progress towards Universal Access: Progress Report. Geneva: World Health Organization, 2011.

7. Joint United Nations Programme on HIV/AIDS. Global Report: UNAIDS Report on the Global AIDS Epidemic. Geneva: Joint United Nations Programme on HIV/AIDS, 2010.

8. Smith-Estelle A, Gruskin S. Vulnerability to HIV/STIs among Rural Women from Migrant Communities in Nepal: A Health and Human Rights Framework. Reproductive Health Matters. 2003 11//;11(22):142-51.

9. Ministry of Health and Population Nepal. Nepal Demographic and Health Survey 2011. Kathmandu, Nepal: Ministry of Health and Population, 2012 March. Report No.

10. Central Bureau of Statistics. National Population and Housing Census 2011. Kathmandu: National Planning Commision, 2012.

11. Ruxrungtham K, Brown T, Phanuphak P. HIV/AiDS in Asia. The Lancet. 2004;364(9428):69-82.

12. National Centre for AIDS and STD Control. Factsheet $N^{\circ} 1$ : HIV Epidemic Update of Nepal, as of August 2010. Teku, Kathmandu: Ministry fo Health and Population; 2010.

13. National Centre for AIDS and STD Control. Factsheet $N^{\circ} 1$ : HIV Epidemic Update of Nepal, as of July, 2012. Teku, Kathmandu: Ministry of Health and Population; 2012.

14. Singh S, Mills E, Honeyman S, Krishna Suvedi B, Prasad Pant N. HIV in Nepal: Is the Violent Conflict Fuelling the Epidemic? PLOS Med. $2005 ; 2(8): \mathrm{e} 216$.

15. Upreti BC. The Maoist Insurgency in Nepal: Nature, Growth and Impact. South Asian Survey. 2006;13(1):35-50.

16. Vaidya N, Wu J. HIV epidemic in Far-Western Nepal: effect of seasonal labor migration to India. BMC Public Health. 2011 2011/05/13;11(1):111. English.

17. Chandrasekaran P, Dallabetta G, Loo V, Rao S, Gayle H, Alexander A. Containing HIV/AIDS in India: the unfinished agenda. The Lancet Infectious Diseases. 2006 8//;6(8):508-21.

18. Bryan A, Bryan J, Fisher T. Determinants of HIV risk among Indian truck drivers. Social science \& medicine. 2001;53(11):1413-26.

19. Poudel KC, Okumura J, Sherchand JB, Jimba M, Murakami I, Wakai S. Mumbai disease in far western Nepal: HIV infection and syphilis among male migrant-returnees and non- migrants. Tropical Medicine \& International Health. 2003;8(10):933-9.

20. Dude A. HIV infection, genital symptoms and sexual risk behavior among Indian truck drivers from a large transportation company in South India.(HIV Research)(Survey). Journal of global infectious diseases. 2009;1(1):21. 
21. Maharjan A, Maharjan S, Bauer B. Do Rural Women Who Stay Behind Benefit from Male Out-migration? A Case Study in the Hills of Nepal. Gender, technology and development. 2012;16(1):95-123.

22. Steinbrook R. HIV in India - A Complex Epidemic. New England Journal of Medicine. 2007;356(11):1089-93. PubMed PMID: 17360986.

23. Weine S, Kashuba A. Labor Migration and HIV Risk: A Systematic Review of the Literature. AIDS and Behavior. 2012 2012/08/01;16(6):160521. English.

24. Silverman JG, Raj A, Cheng DM, Decker MR, Coleman S, Bridden C, et al. Sex Trafficking and Initiation-Related Violence, Alcohol Use, and HIV Risk Among HIV- Infected Female Sex Workers in Mumbai, India. Journal of Infectious Diseases. 2011 December 1, 2011;204(suppl 5):S1229-S34.
25. Sarkar K, Bal B, Mukherjee R, Saha MK, Chakraborty S, Niyogi SK, et al. Young age is a risk factor for HIV among female sex workers--an experience from India. The Journal of infection. 2006 10/;53(4):255-9.

26. Puri M, Cleland J. Sexual behavior and perceived risk of HIV/AIDS among young migrant factory workers in Nepal. Journal of Adolescent Health. 2006 3//;38(3):237-46.

27. Nepal VP, Ross MW. Issues Related to HIV Stigma in Nepal. International Journal of Sexual Health. 2010 2010;22(1):20-31. PubMed PMID: WOS:000283319000004.

28. Ishikawa N, Pridmore $\mathrm{P}$, Carr-Hill R, Chaimuangdee $\mathrm{K}$. The attitudes of primary schoolchildren in Northern Thailand towards their peers who are affected by HIV and AIDS. AIDS Care. 2011 2011/02/01;23(2): 237-44. 